\title{
A cadaveric study quantifying the anatomical landmarks of the facial artery and its parapharyngeal branches for safe transoral surgery
}

\begin{tabular}{|r|l|}
\hline Journal: & Head \& Neck \\
\hline Manuscript ID & HED-19-0320.R2 \\
\hline Wiley - Manuscript type: & Original Article \\
\hline Date Submitted by the \\
Author: & n/a \\
\hline Complete List of Authors: & $\begin{array}{l}\text { Mohamed, Aziza; Keele University, Faculty of Medicine } \\
\text { Paleri, Vinidh; Royal Marsden NHS Foundation Trust, Head and Neck } \\
\text { Surgery } \\
\text { George, Ajith; Keele University, Keele Anatomy and Surgical Training } \\
\text { Centre }\end{array}$ \\
\hline Key Words: & Anatomy, Trans Oral, Facial Artery, Parapharyngeal, Surgery \\
\hline & \\
\hline
\end{tabular}

\section{SCHOLARONE Manuscripts}


A cadaveric study quantifying the anatomical landmarks of the facial artery and its parapharyngeal branches for safe transoral surgery

1. Aziza Mohamed, $\mathrm{MSc}^{1}$

2. Vinidh Paleri, MBBS, MS, FRCS (ORL-HNS), FRCS, CSiG²

3. Ajith George, MBChB, FRCS (ORL-HNS) ${ }^{1,3}$;

${ }^{1}$ Keele University Medical School, Staffordshire, United Kingdom,

${ }^{2}$ Royal Marsden Hospital, London, England, United Kingdom,

${ }^{3}$ University Hospitals North Midlands, North Staffordshire, England, United Kingdom

Correspondence:

Mr Ajith George

David Weatherall Building

Keele Medical School

Staffordshire

United Kingdom

ST5 5BG

a.george@keele.ac.uk

Key words:

Anatomy

Trans-oral

Surgery

Facial artery

Parapharyngeal 


\begin{abstract}
Background

Haemorrhage remains a major potential risk when performing any form of transoral surgery. This is the first study to focus on the location of the facial artery 'bulb' (FaB) and its tonsillar branches within the parapharyngeal space (PPS) from the perspective of the trans oral surgeon.
\end{abstract}

Method

A total of 44 hemi-sections were dissected via the transoral approach with endoscopic assistance; 26 from fresh-frozen specimens and 18 formalin-fixed hemi-sections. The distance from the superior apex of the FaB to the Pterygoid Hamulus $(\mathrm{PH})$ was recorded and the arterial branching variations described.

Results

The average distance from the $\mathrm{PH}$ to the $\mathrm{FaB}$ was $4.17 \pm 0.4 \mathrm{~cm}$. In $90.9 \%$ of cases the two tonsillar artery branches passed between styloglossus muscle (SGM) and stylopharyngeus muscle (SPM)

Conclusion

Understanding the FaB location and its branching patterns offers the surgeon confidence dissecting in the parapharyngeal space transorally. 


\section{Background}

Strategies to reduce postoperative morbidity from transoral approaches such as TOES (endoscopic), TORS (robotic) and TOLS (LASER) in the head and neck are valuable considering the recent surge in popularity of these techniques. Whilst these newer approaches aim to surgically resect tumours decreasing post-operative stay and functional disruption, many surgeons are apprehensive about operating in this region via a limited access approach. The description of anatomy and techniques for the transoral approach is somewhat limited and often repeated in the current literature (13). Adding to this body of knowledge would enhance the surgeons ability to safely navigate the PPS whilst limiting inadvertent risk to major vessels ${ }^{(4,5)}$. Transcervical arterial ligation of the Fa, Lingual artery (La) and Ascending Pharyngeal Artery (APha) during concurrent or neo adjuvant neck dissection is currently utilised in order to reduce this risk, and evidence is reported to suggest its significance in reducing the risk of haemorrhage postoperatively ${ }^{(6)}$.

Transcervically the FaB is not normally identified as it passes postero-medial to the posterior belly of digastric soon after branching from the external carotid (fig 1). The $\mathrm{Fa}$ is often encountered in sub-mandibular gland surgery distal to the FaB. By this stage it will have already given off the tonsillar branches.

The $\mathrm{FaB}$ is the first major vessel encountered during parapharyngeal dissection intraorally. It has a close association with the La for which it is commonly confused with. This study aims to describe the location of the vascular structures in the PPS, with particular focus on the FaB as it loops into the PPS and the two branches from it that supply the tonsil. 


\section{Materials \& Methods}

Ethics approval for image permissions were obtained from the Ethics Committee at Keele University, North Staffordshire, United Kingdom. Twenty-two cadavers - with no head or neck pathology, malformations or surgery were included in the study. A total of 44 specimens were dissected; twenty-six whole head fresh-frozen specimens were dissected transorally and these were correlated with transcervical dissection of eighteen sagittal sectioned formalin-fixed specimens.

For transoral dissection, the anatomical contents of the lateral oropharynx and the PPS were described as seen transorally. To gain access into the oral cavity, a BoyleDavis mouth gag was secured onto a scaffold bridge whilst the tongue was anteriorly retracted using a 1.0 midline silk suture. In a cranial to caudal direction, the initial incision from the pterygoid hamulus $(\mathrm{PH})$ of the medial pterygoid plate to the retromolar trigone, was made along the pterygomandibular raphe (Figure 2).

The superior constrictor muscle (SCM) was retracted medially and medial pterygoid muscle (MPM) tendon identified. The FaB was subsequently identified in the PPS and its distance from the $\mathrm{PH}$ was recorded in each hemi-section using surgical tape (accuracy, $\pm 0.5 \mathrm{~mm}$ ) and digital calipers. Measurements were recorded three times and the mean was calculated, the findings were then statistically analysed based on side of hemi-section and cadaver type.

Upon identifying the bulb, the palatine branches of the Fa; the tonsillar artery (Ta) and ascending palatine artery ( $\mathrm{APa}$ ) were traced from their origin to the plane of dissection in the PPS. Their relationship to the SGM and SPM muscles were described. 
Concurrent transcervical dissection was performed to confirm the location and presence of the vascular contents. The sagittal sectioned formalin-fixed cadavers were examined with an open style approach and the findings compared to the fresh-frozen specimens. Digital photographs were taken using a Karl-Storz $30^{\circ} 10 \mathrm{~mm}$ diameter endoscope, to document the location of the FaB and its palatine branches in the PPS. 


\section{Results}

The pterygomandibular raphe marked the origin of the superior constrictor from the buccinator muscle and was a window into the PPS. After opening the full length of the raphe, taking care not to injure the lingual nerve inferiorly, dissection lateral to the superior constrictor revealed the contents of the pre-styloid compartment of the PPS. At the superior aspect of the incision the tendon of the MPM was seen and used to identify the buccopharyngeal fascia overlying the SCM. Inferiorly the SGM was identified as the next deep plane landmark of dissection. The Fa was identified as the third branch of the ECa in $88.6 \%$ (39/44), arising directly from it, or from the linguofacial trunk in the remaining $11.4 \%(5 / 44)$. The FaB was located by dissecting the PPS inferior and lateral to the SGM. Medial displacement of the SGM near its insertion of its oblique slip joining the hyoglossus muscle revealed the space of dissection to find the FaB (figure 3). Immediately after branching from the external carotid the Fa ascended superiorly and looped over the posterior belly of the digastric/stylohyoid muscle complex in a posterior to anterior direction before piercing the submandibular gland. The distance recorded from the bony tip of the PH to the apex of the FaB (Figure 3) in all the dissections completed was $4.17 \pm 0.40 \mathrm{~cm}$. There was no statistically significant difference of this measurement between sides $(p=0.53)$, the origin of the Fa $(p=0.95)$ or the cadaveric specimen type $(p=0.08)$. The FaB was identified as the site of origin of the two tonsillar branches. Both the APa and Ta originated from the Fa directly (Figure 4). The ascending palatine artery was identified as the first branch of the $\mathrm{Fa}$ in $88.6 \%(39 / 44)$ of the hemi-sections, $6.8 \%(3 / 44)$ of cases originating directly from the ECa and the remaining 4.5\% (2/44) of cases the artery was absent. Both the $\mathrm{APa}$ and $\mathrm{Ta}$ travelled together after branching from the FaB. In 90.9\% (40/44) of dissections, these branches passed between the SGM and the SPM to pierce the SCM 
of the lateral pharyngeal wall and supply the tonsil. In $4.5 \%(2 / 44)$ of cases, the branches crossed ventral to the SGM to enter into the PPS and in $2.3 \%(1 / 44)$ of cases, the branches crossed dorsal to both the SGM and SPM (figure 3). 


\section{Discussion}

The relative proximity of the FaB to the lateral aspect of the SGM places this vessel at considerable risk during transoral surgery. It is especially vulnerable to injury if the SGM needs to be resected for clear margins. The importance of SGM anatomy has been reiterated by Laccourreye et $\mathrm{al}^{7}$ in terms of improving safety and accuracy of surgery in the PPS. Quantifying the location of the FaB is of great importance adds to the importance of relations to the SGM. Previous studies dissected and recorded results only from silicone injected vessels in fresh-frozen cadavers ${ }^{(2,8-11)}$ from an anterior approach with no mention of the facial artery bulb or its relevance.

This study is the first to include the measurement between the $\mathrm{PH}$ and the FaB. The distance measured from the $\mathrm{PH}$ to the $\mathrm{FaB}$ was approximately $4 \mathrm{~cm}$ across all specimens dissected. There was no statistically significant difference between the cadaver types leading to the proposal that its location in vivo is also consistent. The authors accept limited applications of the $4 \mathrm{cms}$ measurement in clinical practice however this finding does infer consistency with the locality of the FaB which has previously not been described from a trans-oral perspective in the literature.;

Identifying and locating the FaB provides a better awareness of its location particularly if resection of large tumour bulk invades beyond the SCM. Dissection lateral to the SGM in this region can lead to injury of the FaB and significant haemorrhage. In video recorded dissections of transoral surgery to date this vessel is often mistaken for the lingual artery. This incorrect assumption is likely based upon the proximity to the base of tongue. We found in the hemi-sections that the lingual and facial vessels are indeed related to the $\mathrm{FaB}$ but are found deeper in the dissection. Despite variations of the 
origins of the $\mathrm{La}$ and $\mathrm{Fa}$, such as the $11.4 \%$ of cases where the facial and lingual shared one common trunk, the presence or the location of the FaB is not affected.

Moreover, from the trans cervical perspective, the bulb lies deep to the posterior belly of digastric and stylohyoid muscle. This is relevant as identification of the bulb itself does not lead to a "breach" into the neck necessitating some form of soft tissue repair.

Anatomical relations in the PPS to aid the surgeon have been described. Duvvuri et al had examined the relationship between the ascending pharyngeal artery and SGM ${ }^{(8)}$ but these are two soft tissue structures. Whilst the SGM remains an important landmark and structure that protects the ECa and its branches, it can be displaced due to tumour bulk. Furthermore, if the SGM needs to be removed from the PPS, the distances quoted cannot be reliably used intraoperatively.

This is the first anatomical study to describe PPS dissection is such detail and relevance to the operator. Using our data, we can establish a safe method of dissection in this region particularly when resecting tonsillar malignancies. All types of transoral surgery can benefit from this information, However, there are advantages of using TORS with increased magnification, three-dimensional visual perception, precision and increased degrees of freedom (5). User experience is certainly more relevant than the method of operating in this setting.

Surgeons are all too aware of the major vessels in this region, particularly the ECa and internal carotid. Perhaps less well described has been the tonsillar branches and in particular their relationship to the SGM/SPM complex. As the majority of dissections demonstrated the vessels pass through the SGM and SPM we propose that the SGM is a safe soft tissue plane of dissection, but one must proceed with caution in the $4.5 \%$ of cases where this vessel would lie on top of the SGM. The vessel is easily identified 
and can be ligated with vascular clips. We support the current evidence that demonstrates that early ligation of arterial vessels either during staged or concurrent neck dissection considerably reduces this risk of postoperative haemorrhage ${ }^{(6)}$.

Initial safe dissection proceeds through the buccopharyngeal fascia after incision into the pterygomandibular raphe. Finding the tendon of the MPM helps the surgeon correctly identify a safe and correct plane between the SCM and the MPM. The dissection can then proceed inferiorly towards the SGM.

We acknowledge some limitations to the study due to restrictions with dissection as no saline or latex was injected into the vessel lumens, thereby reducing the true vascular diameter of the vessels studied potentially altering measurement by a few millimetres. However, one cannot quantify the effect of peri operative vessel ligation on these arteries in vivo so this must be taken into context. 


\section{Conclusions}

The distance from the $\mathrm{PH}$ to the apex of the $\mathrm{FaB}$ is consistently around $4 \mathrm{~cm}(4.17+$ $0.4 \mathrm{~cm}$ ) and this knowledge serves to readily identify and preserve the Fa from direct damage during transoral surgery of the PPS. The PH is a consistent landmark that can be utilised during transoral surgery into the lateral oropharynx and base of tongue. The facial artery branches to the tonsil most commonly pass below the SGM therefore making this muscle a safe deep plane of dissection tumour permitting. 


\section{Author Contributions}

Aziza Abdulhalim Mohamed, study design, data acquisition, data analysis, drafting work.

Ajith Paulose George, study design, critical review and drafting of work, final approval of work, accountable for all aspects of the work.

Vinidh Paleri- Critical Review of work and final approval

\section{Disclosures}

Competing interests: Ajith Paulose George - Medical Director, Endoscope-i Ltd.

Sponsorships: None

Funding source: None

Conflict of interests: None 


\section{References}

1. Moore EJ, Janus J, Kasperbauer J. Transoral robotic surgery of the oropharynx: Clinical and anatomic considerations. Clin Anat [Internet]. 2012 Jan [cited 2018 Jun 23];25(1):135-41. Available from:

http://doi.wiley.com/10.1002/ca.22008

2. Gun R, Durmus K, Kucur C, Carrau RL, Ozer E. Transoral Surgical Anatomy and Clinical Considerations of Lateral Oropharyngeal Wall, Parapharyngeal Space, and Tongue Base. Otolaryngol Neck Surg [Internet]. 2016 Mar 26 [cited 2018 Jun 11];154(3):480-5. Available from: http://www.ncbi.nlm.nih.gov/pubmed/26814206

3. Weinstein GS, O'Malley BW, Snyder W, Sherman E, Quon H. Transoral Robotic Surgery. Arch Otolaryngol Neck Surg [Internet]. 2007 Dec 1 [cited 2018 Jun 22];133(12):1220. Available from:

http://archotol.jamanetwork.com/article.aspx?doi=10.1001/archotol.133.12.122 0

4. Pollei TR, Hinni ML, Moore EJ, Hayden RE, Olsen KD, Casler JD, et al. Analysis of Postoperative Bleeding and Risk Factors in Transoral Surgery of the Oropharynx. JAMA Otolaryngol Neck Surg [Internet]. 2013 Nov 1 [cited 2018 Jun 28];139(11):1212. Available from:

http://archotol.jamanetwork.com/article.aspx?doi=10.1001/jamaoto.2013.5097

5. Hay A, Migliacci J, Zanoni DK, Boyle JO, Singh B, Wong RJ, et al. Complications following transoral robotic surgery (TORS): A detailed institutional review of complications. Oral Oncol [Internet]. 2017 [cited 2018 
Mar 6];67:160-6. Available from: https://ac.elscdn.com/S1368837517300453/1-s2.0-S1368837517300453-

main.pdf?_tid=d9a33735-9808-41f0-9cf3a449962f3124\&acdnat=1520333046_815ff2e377d997d7e7e211aa90a1e7c8

6. Hay A, Migliacci J, Karassawa Zanoni D, Boyle JO, Singh B, Wong RJ, et al. Haemorrhage following transoral robotic surgery. Clin Otolaryngol [Internet]. 2018 Apr [cited 2018 Jun 10];43(2):638-44. Available from: http://www.ncbi.nlm.nih.gov/pubmed/29194991

7. Laccourreye O, Orosco RK, Rubin F, Holsinger FC. Styloglossus muscle: a critical landmark in head and neck oncology. Eur Ann Otorhinolaryngol Head Neck Dis 2018 Dec; 135(6):421-425

8. Lim CM, Mehta V, Chai R, Pinheiro C-ND, Rath T, Snyderman C, et al. Transoral anatomy of the tonsillar fossa and lateral pharyngeal wall: Anatomic dissection with radiographic and clinical correlation. Laryngoscope [Internet]. 2013 Dec [cited 2018 Jun 11];123(12):3021-5. Available from: http://www.ncbi.nlm.nih.gov/pubmed/24105605

9. Wang C, Kundaria S, Fernandez-Miranda J, Duvvuri U. A description of arterial variants in the transoral approach to the parapharyngeal space. Clin Anat [Internet]. 2014 Oct [cited 2018 Jun 10];27(7):1016-22. Available from: http://www.ncbi.nlm.nih.gov/pubmed/24510490

10. Dallan I, Seccia V, Muscatello L, Lenzi R, Castelnuovo P, Bignami M, et al. Transoral endoscopic anatomy of the parapharyngeal space: A step-by-step logical approach with surgical considerations. Head Neck [Internet]. 2011 Apr 
[cited 2018 Jun 11];33(4):557-61. Available from:

http://doi.wiley.com/10.1002/hed.21488

11. Weinstein G, O'Malley BW. Transoral Robotic Surgery (TORS). 1st ed. Plural Publishing; 2012. 59-68 p. 


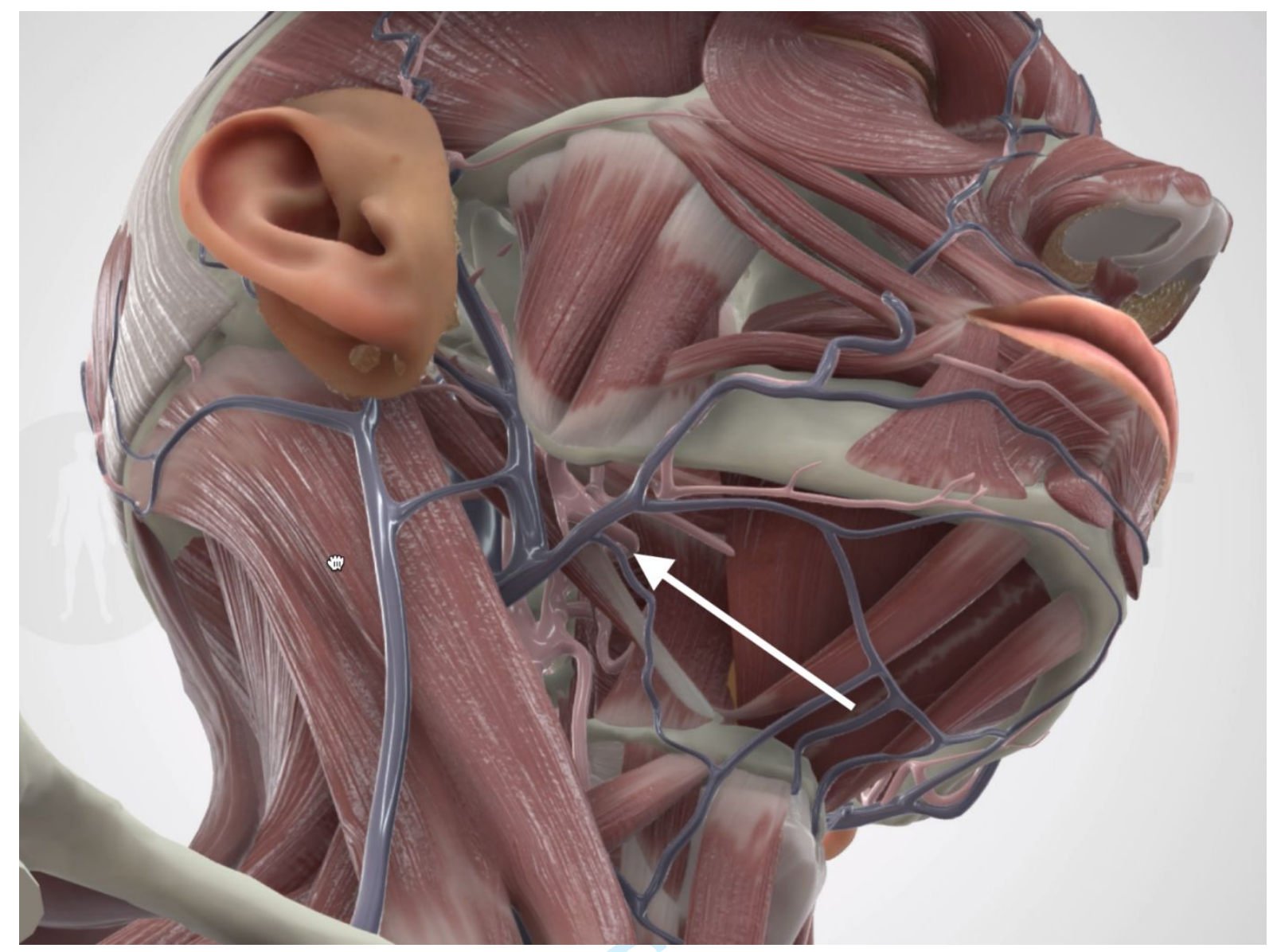

Figure 1 Diagram illustrating the facial artery bulb (white arrow) from the trans cervical perspective. Reproduced with permission from anatomynext.com 


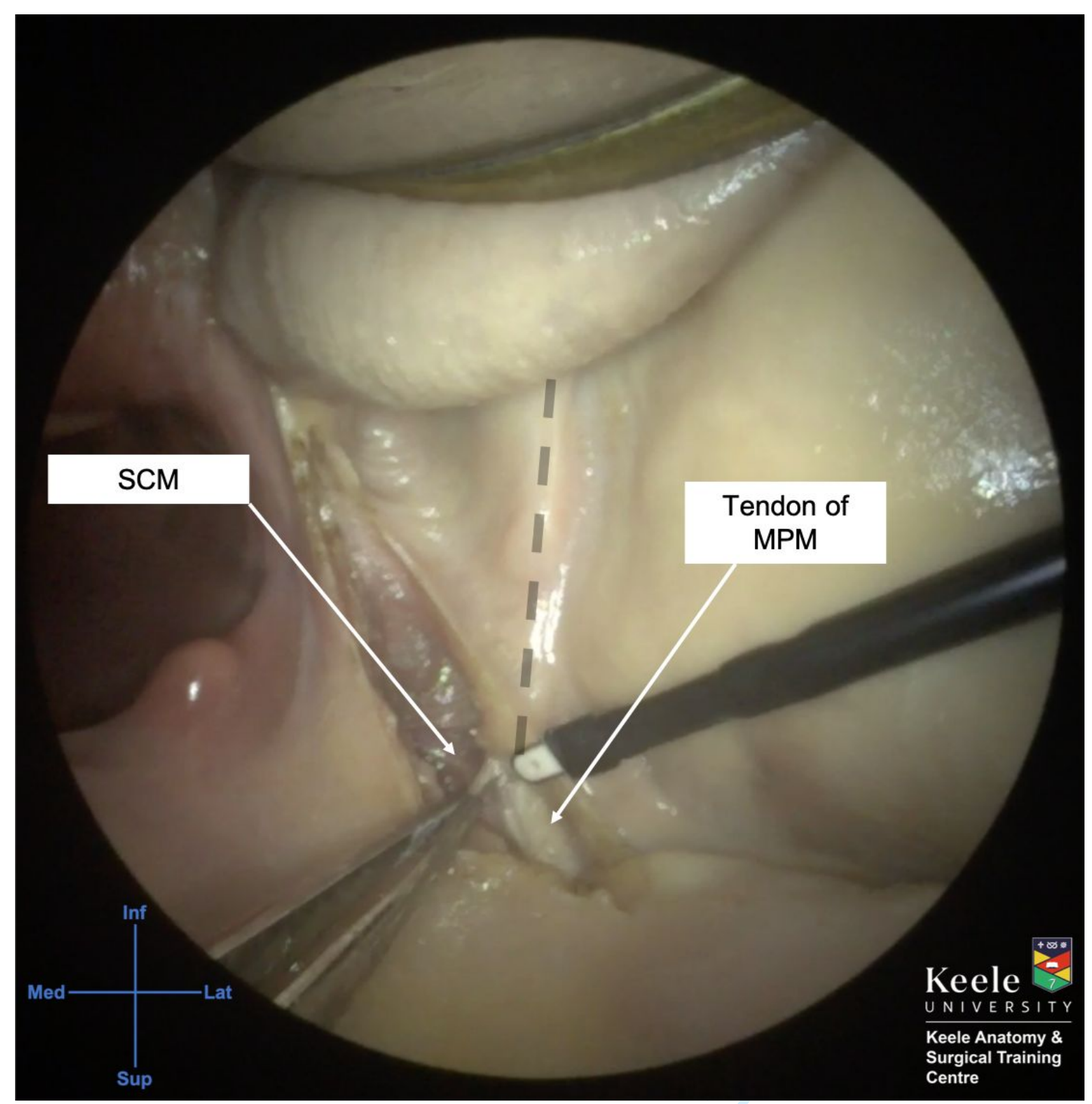

Figure 2 Endoscopic Right sided dissection demonstrating the initial superior dissection landmarks in the PPS, identifying the tendon of the Medial Pterygoid. The buccopharyngeal fascia is being grasped with the forceps on the left. The dashed line represents the Pterygomandibular raphe 


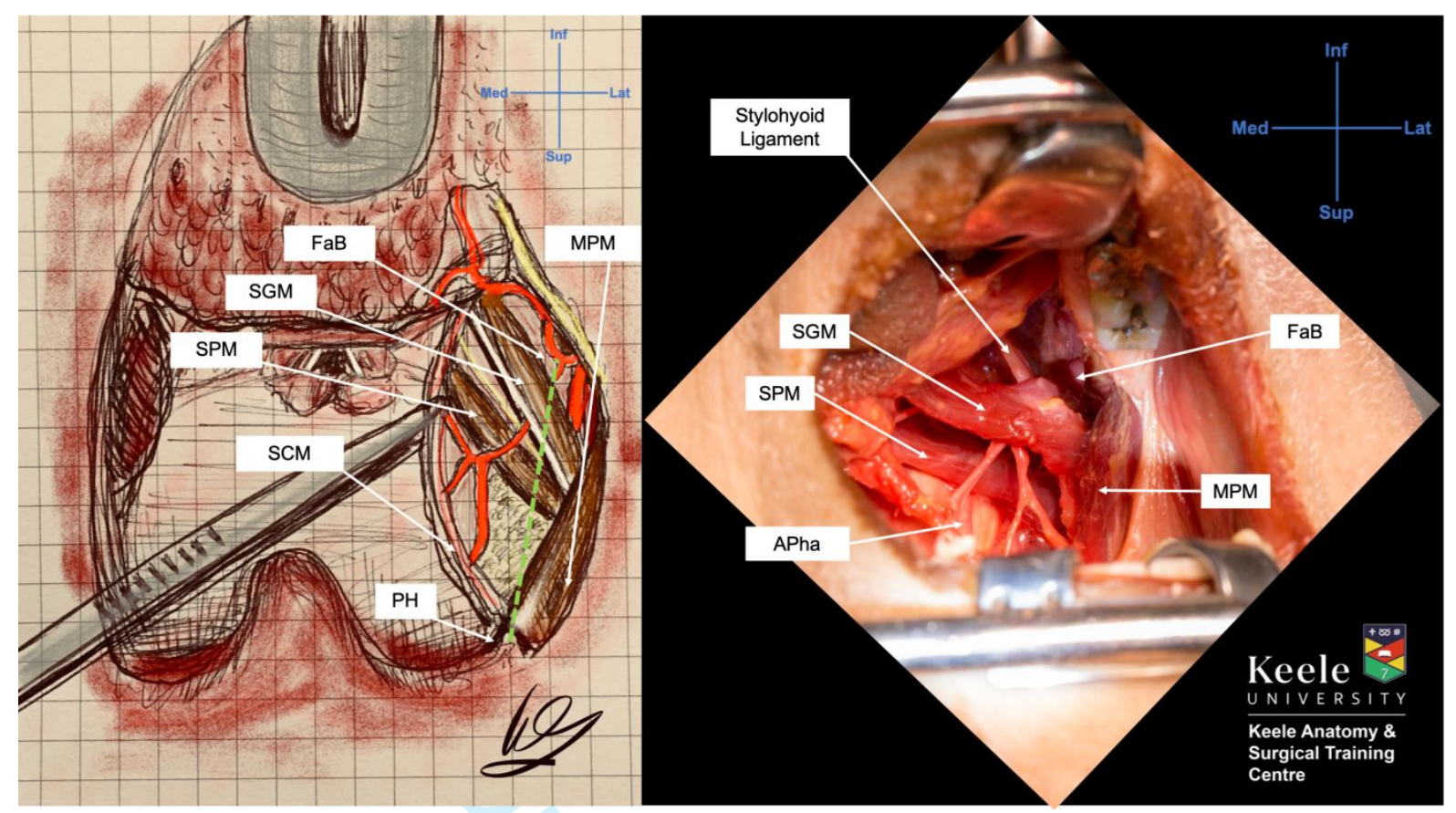

Figure 3 (left) Senior author (AG) illustration of right sided transoral dissection through the pterygomandibular raphe demonstrating the measurement between the $\mathrm{PH}$ and apex of the $\mathrm{FaB}$ (green dotted line). In the digital photo (right) the superior constrictor muscle has been retracted for access. Note the location of the bulb inferior and lateral to the SGM. (approx. $4.17 \mathrm{cms}$ from the $\mathrm{PH}$ ) One tonsillar branch is seen arising from the FaB passing between the SGM and SPM (the most common branching pattern). The SGM/SPM are also medialised with sutures in this image to demonstrate the FaB. Their normal anatomical positions are in the orientation of the stylohyoid ligament. 


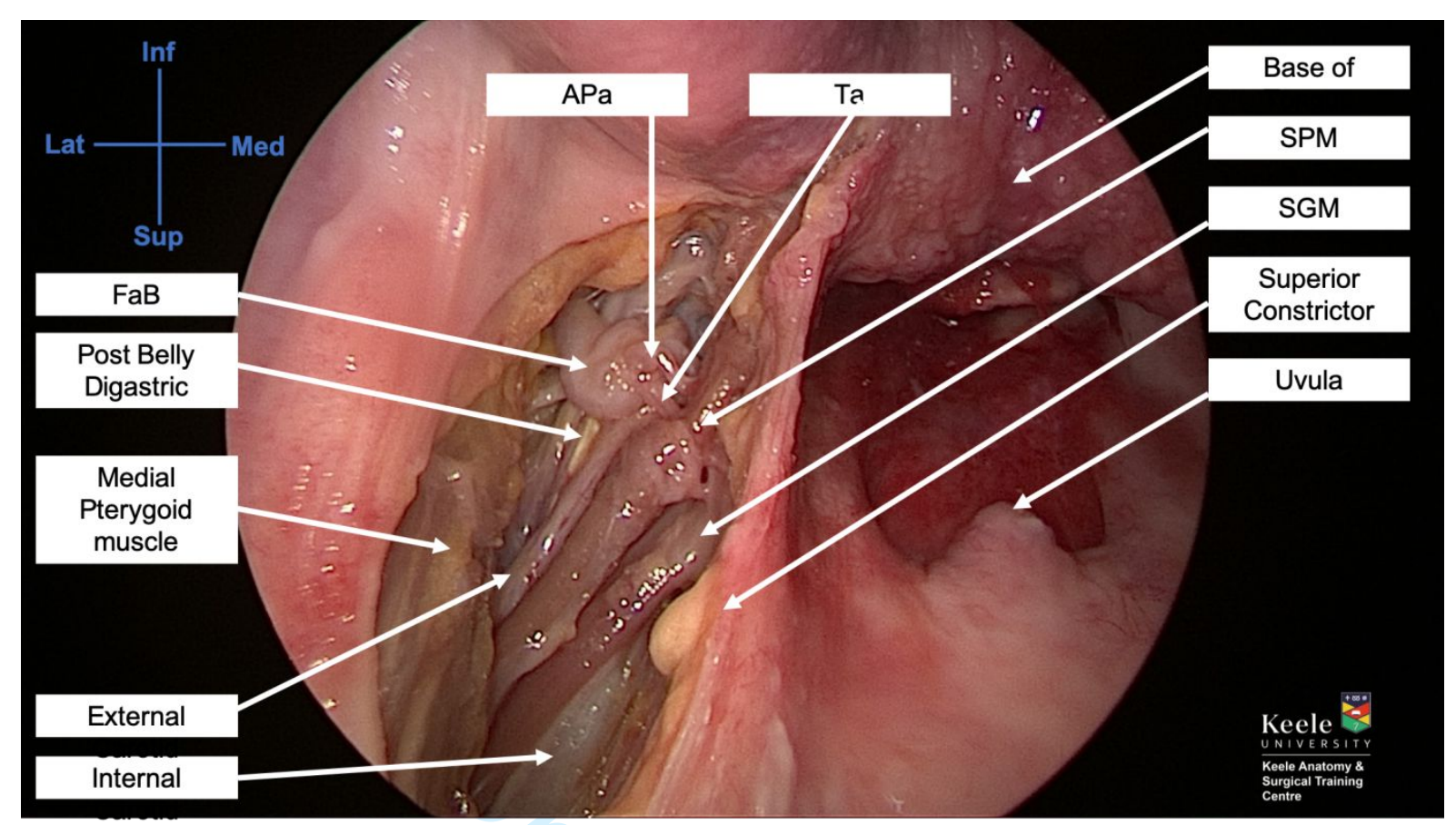

Figure 4 Endoscopic left sided transoral view demonstrating the $\mathrm{APa}$ and $\mathrm{Ta}$ coming directly from the $\mathrm{FaB}$. In this dissection both vessels are seen passing dorsal to the SGM and SPM. Medially the FaB will have originated from the external carotid and laterally the Fa continues to pierce into the Sub mandibular gland eventually becoming the angular artery on the face. Note the external carotid lateral and protected by the SGM/SPM complex whilst the Internal Carotid is seen lying deep to the SPM after removal of parapharyngeal fat. 